\title{
PHYTOCHEMICAL INVESTIGATION OF CHENOPODIUM MURALE (FAMILY: CHENOPODIACEAE) CULTIVATED IN IRAQ, ISOLATION AND IDENTIFICATION OF SCOPOLETIN AND GALLIC ACID
}

\author{
OMER H AHMED ${ }^{1 *}$, MAHA N HAMAD ${ }^{2}$, NOOR S JAAFAR ${ }^{2}$ \\ ${ }^{1}$ Department of Pharmacognosy and Medicinal Plants, College of Pharmacy, University of Tikrit, Tikrit, Iraq. ${ }^{2}$ Department of \\ Pharmacognosy and Medicinal Plants, College of Pharmacy, University of Baghdad, Baghdad, Iraq. Email: omeracino@yahoo.com
}

Received: 11 June 2017, Revised and Accepted: 22 July 2017

\section{ABSTRACT}

Objective: The aim of our study was to investigate chemical constituents of leaves of Chenopodium murale since no phytochemical investigation had been done previously in Iraq.

Methods: Leaves of $C$. murale were macerated in absolute methanol for 2 days and fractionated by petroleum ether, chloroform, ethyl acetate, and n-butanol. The ethyl acetate fraction was analyzed by high-performance liquid chromatography (HPLC) and high-performance thin-layer chromatography (HPTLC) for its phenolic acid and coumarins contents. Coumarin derivative and phenolic acid were isolated from this fraction and identified by gas chromatography/mass spectrometry, infrared, ultraviolet, HPLC, and HPTLC.

Results: The different chromatographic and spectroscopic results revealed the presence of gallic acid and coumarin.

Conclusion: The results of the current study showed the presence of scopoletin and gallic acid in the ethyl acetate fraction of $C$. murale.

Keywords: Chenopodium murale, Coumarins, Phenolic acid, High-performance liquid chromatography, High-performance thin-layer chromatography. (C) 2017 The Authors. Published by Innovare Academic Sciences Pvt Ltd. This is an open access article under the CC BY license (http://creativecommons. org/licenses/by/4. 0/) DOI: http://dx.doi.org/10.22159/ajpcr.2017.v10i11.20504

\section{INTRODUCTION}

Chenopodiastrum murale [1] (Syn. C. murale) is a species of plant in them amaranth family known by the common names nettle-leaved goosefoot [2], Australian-spinach, salt-green, and sowbane [3]. This plant is native to Europe and parts of Asia and Northern Africa, but it is widespread worldwide, particularly in tropical and subtropical areas due to its being easily introduced [3]. This plant belongs to the family Chenopodiaceae also called as goosefoot family that contains about 102 genera and 1400 species of annual and perennial herbs and shrubs scattered throughout the world [4]. The genus Chenopodium consists of 200 species [5]. The importance of Chenopodium species is due to their wide variety of medicinal properties. Plants belonging to this genus are reported to have wide applications in folk medicines, as an anthelmintic, stomachic, antispasmodic, diaphoretic, emmenagogue, for the pain of amenorrhea, as an abortifacient and for the relief of asthma, catarrh, and migraine [6,7]. Some flavonoids isolated from C. murale showed antihypertensive activity [8]. Various Chenopodium species have been reported to have anthelmintic properties [9]. Chemical studies of members of this genus have been concerned with essential oils [10,11]; a wide variety of flavonoids [12-14]; sterols and steroidal estrogens like substances [15,16]; and alkaloids and coumarins $[17,18]$. Four flavonol glycosides, three aglycones, and one coumarin were isolated from the aerial parts of C. murale. One of the glycosides, kaempferol 3-rhamnoside-7xylosyl $(1 \rightarrow 2)$-rhamnoside, is new. The other known compounds include kaempferol, its 7-rhamnoside, 3-rhamnoside 7-glucoside and 3,7-dirhamnoside, herbacetin, quercetin, and scopoletin [19]. C. murale leaves are a source of Vitamins A and C, and calcium of all the Chenopodiaceae, C. murale, was found to have the highest levels of oxalic acid, which leads some to recommend that it be eaten in moderation (similar to spinach) [20].

Scopoletin is a derivative of coumarin [21], it is a benzopyran in nature, and its chemical name is 7-hydroxy-6-methoxycoumarin [22,23].
Scopoletin possesses antioxidant property and scavenged superoxide anion in the xanthine/xanthine oxidase reaction system in a concentration-dependent manner [24]. Scopoletin has hypotensive effect [25]. It also shows antidepressant, angiogenic, and antifungal activity [26-29]. Scopoletin is coumarin derivative and coumarin is reported for hypoglycemic activity.

Accumulation of scopoletin has been correlated with resistance to microbial attack and other stresses, such as mechanical injury and dehydration [30]. Scopoletin often seems to be the most important product rising in concentration in the infected plant as compared to other related coumarins and coumarin glycosides such as scopolin (the glycoside of scopoletin), esculetin, and esculin [31-33]. In the certain types of cancer, scopoletin inhibited proliferation of certain cancer cells by inducing apoptosis $[34,35]$. Scopoletin was found to inhibit hepatic lipid peroxidation and increased the activity of antioxidants, superoxide dismutase, and catalase. A few studies suggested that scopoletin might benefit those at risk of high cholesterol, triglyceride, and glucose levels [36]. Its major unwanted side effect of scopoletin probably is increased bleeding time [37]. Furthermore, scopoletin was reported for its interesting pharmacological activities which were antithyroid, antihyperglycemic, immunomodulatory effect on tumoral and normal lymphocytes, antiproliferation, vasorelaxant, antipyretic, antiplatelet aggregation, antidiabetes, applications in cardiovascular disease, neuroprotective, antimicrobial, anti-inflammatory, inhibition the release of prostaglandin E2, and suppressed the expression of cyclooxygenase-2 [38]. Gallic acid elicits several interesting and various biological responses, such as antibacterial, antifungal, antiinflammatory, antiviral, anticancer, antioxidant, antimutagenic, and antidiabetic activities. Due to these biological activities, gallic acid could be a good lead compound for new drug development [39].

The main objective of this study was to investigate the coumarin and phenolic acids contents of $C$. murale cultivated in Iraq since there were no previous studies concerning the Iraqi species and also to isolate them from ethyl acetate fraction of cold method. 


\section{METHODS}

\section{Collection of plant materials}

C. murale was obtained from garden of the Department of Pharmacognosy, College of Pharmacy, University of Baghdad. The plant was identified and authenticated by Professor Dr. Sokaena Abass, Department of Biology, College of Sciences, University of Baghdad. A voucher sample was kept at the Department of Pharmacognosy, College of Pharmacy, University of Baghdad.

\section{Equipment and chemical}

The instruments used were rotary evaporator (BÛ̀CHI Rotavapor R-205, Swiss), sonicator (Baranson Sonifier, USA), high-performance liquid chromatography (HPLC) (Shimadzu10AV-LC, Japan), and highperformance thin-layer chromatography (HPTLC) (Eike Reich/CAMAGLaboratory, Switzerland). All chemicals and solvents used were of analytical grade and obtained from Riedel-de Haen, Germany, except trifluoroacetic acid, and methanol which are HPLC grade purchased from Sigma-Aldrich, Germany. The standard scopoletin and gallic acid were purchased from Chengdu Biopurify Phytochemicals, China (purity $>97$ ). Thin-layer chromatography (TLC) aluminum plates pre-coated with silica gel $60 \mathrm{~F} 254(100 \mathrm{~mm} \times 100 \mathrm{~mm}, 0.2 \mathrm{~mm}$ thick $)$ used were obtained from E. Merck Ltd., India.

\section{Extraction}

Leaves of $C$. murale were thoroughly washed and dried on the shade. The dried plant was powdered in a mechanical grinder. $300 \mathrm{~g}$ of leaves powders of $C$. murale were macerated in methanol for 2 days and filtered, and the filtrate was evaporated to dryness under vacuum using rotary evaporator. $10 \mathrm{~g}$ of the residue was suspended in water and subsequently fractionated by partitioning with petroleum ether, chloroform, ethyl acetate, and n-butanol $(100 \mathrm{ml} \times 3)$ for each fraction. The first three organic layers were dried over anhydrous sodium sulfate, filtered, and evaporated to dryness.

\section{Preparations of standards and samples for analysis}

Standard solutions for HPLC of scopoletin and gallic acid were prepared by dissolving $0.04 \mathrm{mg}$ in $1 \mathrm{ml}$ of methanol HPLC grade. Dried samples were prepared for HPLC analysis by dissolving them in methanol and subjecting them to ultrasonication at $60 \%$ duty cycles for 25 minutes at $25^{\circ} \mathrm{C}$ followed by centrifugation at $7500 \mathrm{rpm}$ for 15 minutes. The clear supernatant of each sample was evaporated under vacuum. The residues were resuspended individually, in $1 \mathrm{ml}$ of methanol HPLC grade, homogenizing using vortex mixer, and passing them through $2.5 \mu \mathrm{m}$ disposable filter, and stored at $4^{\circ} \mathrm{C}$ for further analysis. $20 \mu \mathrm{l}$ of the sample was injected into HPLC system for analysis. Standards used for HPTLC analysis (scopoletin and gallic acid) were prepared by dissolving $1 \mathrm{mg}$ of each standard in $1 \mathrm{ml}$ methanol, while the samples were prepared by dissolving few milligrams from each sample in $1 \mathrm{ml}$ methanol.

\section{Preliminary phytochemical investigation \\ Test for flavonoids}

Few milligrams of the ethyl acetate fraction were suspended in ethanol and few drops of $5 \%$ ethanolic $\mathrm{KOH}$ were added, and then, few drops of $5 \% \mathrm{HCl}$ were added. The changes in colors were recorded.

\section{Test for coumarins}

In a small test tube, few milligram of plant extract was covered with filter paper moistened with $1 \mathrm{~N} \mathrm{NaOH}$. The test tube was placed for few minutes in a boiling water bath. After removing the filter paper, it was examined under ultraviolet (UV) light; yellow florescence indicated the presence of coumarins [40].

\section{Test for phenols}

Few milligrams of methanol plant extract were treated with few drops of $1 \% \mathrm{FeCl}_{3}$. Formation of dark greenish-blue color indicates the presence of phenols.
Isolation of coumarin and phenolic acid derivative by preparative TLC

A coumarin and phenolic derivative was isolated by preparative TLC, utilizing ethyl acetate fraction.

\section{Preparation of stationary phase}

Readymade silica gel $\mathrm{GF}_{254}$ plates with a layer thickness of $0.5 \mathrm{~mm}$ dimension $20 \times 20 \mathrm{~cm}$. The plates were reactivated by heating in the oven at $120^{\circ} \mathrm{C}$ for $15-20$ minutes, left to cool, and used for application after allocation of the baseline and the solvent front.

\section{Preparation of mobile phase (solvent system)}

The constituents of the mobile phase for coumarin (chloroform:acetone:formic acid - 75:25:16.5 V/V) and for phenolic acid butanol:acetic acid:water $(4: 1: 5 \mathrm{~V} / \mathrm{V})$ were mixed in a conical flask and introduced in the jar. The jar was lined with a filter paper, closed tightly, and left for saturation.

\section{Application of sample}

About $1 \mathrm{~g}$ of the sample was dissolved in absolute ethanol and applied on the baseline of TLC plates using a capillary tube.

\section{Detection of separated spots}

Detection was done by examination under UV light with two wave lengths, namely, 254 and $366 \mathrm{~nm}$. The purity of each band was checked by analytical TLC till single spot on TLC plate is obtained for identification with reference standard.

\section{HPLC analysis}

HPLC technique (Shimadzu 10AV-LC) was applied for the detection of different constituents found in the ethyl acetate fraction as coumarins, flavonoids, and phenolic acids using a mobile phase composed of $0.05 \%$ trifluoroacetic acid in deionized water (Solvent A), and Solvent B was $0.05 \%$ trifluoroacetic acid in methanol $\mathrm{pH} 2.5$, gradient program from $0 \% \mathrm{~B}$ to $100 \% \mathrm{~B}$ for 15 minutes with flow rate $1.2 \mathrm{ml} / \mathrm{min}$, wavelength $280 \mathrm{~nm}$, and a column nucludar C-18-DB, $3 \mu \mathrm{m}$ particle size (50×20 mm ID).

\section{HPTLC analysis}

Ethyl acetate fraction was analyzed also for its coumarins, flavonoids, and phenolic acids contents utilizing HPTLC (Eike Reich/CAMAGLaboratory, Switzerland), using silica gel $\mathrm{GF}_{254}$ plates developed in a mobile phase composed of chloroform:acetone:formic acid (75:25:16.5) examined at 280 and $366 \mathrm{~nm}$ wavelength.

\section{Identification of isolated coumarin and phenolic derivatives}

The isolated coumarin and phenolic derivatives were identified by different spectroscopic and chromatographic techniques listed below:

- Gas chromatography/mass spectrometry (GC/MS): The GC/MS instrument used was GC/MS-QP 2010 ultra: SHIMADZU/GC GC 2010 Plus.

- Conditions used for GC/MS analysis are the followings:

- Column temperature: $50.0^{\circ} \mathrm{C}$

- Injection temperature: $280.0^{\circ} \mathrm{C}$

- Injection mode: Split less

- Sampling time: 1 minute

- Flow control mode: Pressure

- Pressure: $100.0 \mathrm{kPa}$

- Column flow: $1.2 \mathrm{ml} / \mathrm{min}$

- Linear velocity: $45.4 \mathrm{~cm} / \mathrm{s}$

- Purge flow: $3.0 \mathrm{ml} / \mathrm{min}$.

- Infrared (IR): IR spectra for coumarin was recorded in $\mathrm{KBr}$ disk, the range of scanning $4000-400 \mathrm{~cm}^{-1}$

- UV: Few milligrams of scopoletin were dissolved in $1 \mathrm{ml}$ absolute methanol, and its UV absorbance was scanned from 200 to $400 \mathrm{~nm}$

- HPLC: As listed before

- HPTLC: As listed before. 


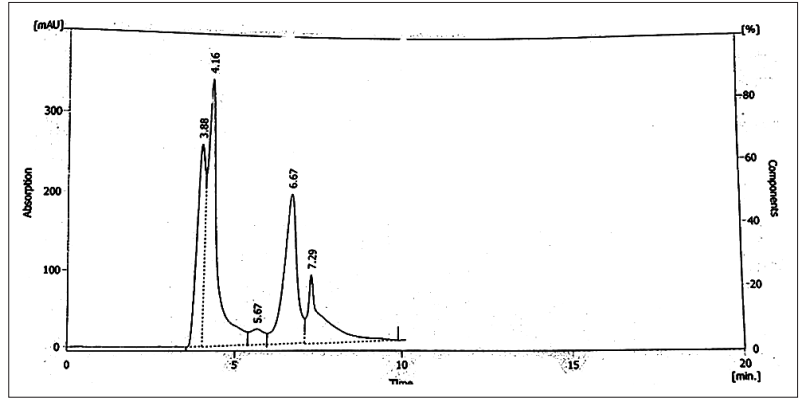

Fig. 1: High-performance liquid chromatography chromatogram of ethyl acetate fraction

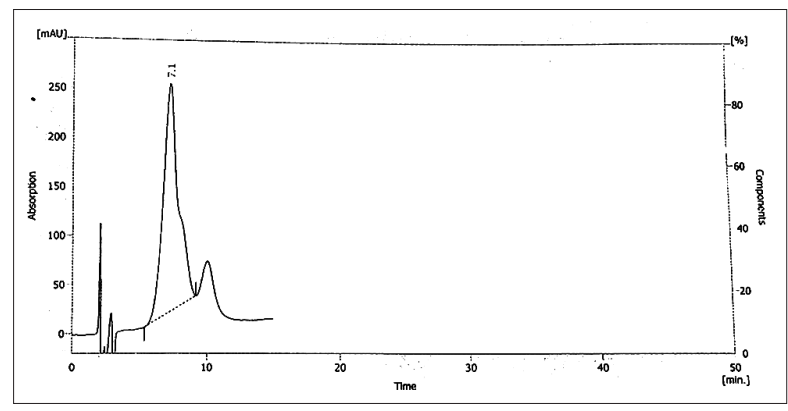

Fig. 2: High-performance liquid chromatography chromatogram standard scopoletin

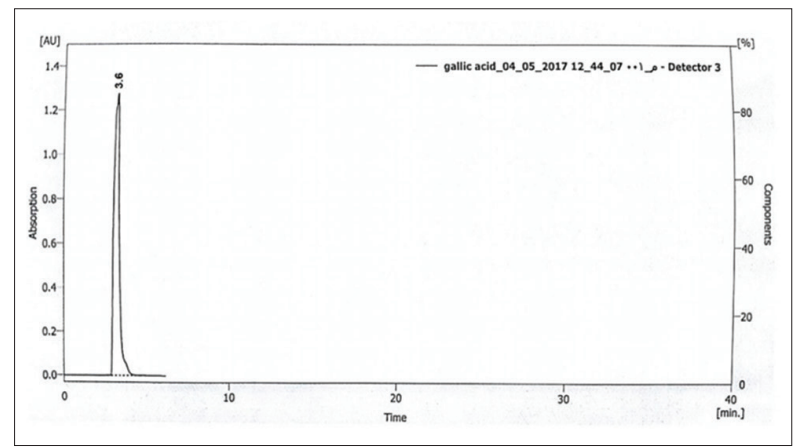

Fig. 3: High-performance liquid chromatography chromatogram standard of gallic acid

\section{RESULTS}

Preliminary examination of the ethyl acetate fraction results is shown in Table 1.

The HPLC results of analyzed ethyl acetate fraction show the presence of the listed compounds according to their retention times shown in the Table 2 and their chromatograms in Fig. 1 compared with that of standard scopoletin and gallic acid shown in Figs. 2 and 3, respectively.

HPTLC results are shown in Fig. 4. Preparative TLC chromatograms used for isolation of coumarin are shown in Fig. 5. Preparative TLC chromatograms for phenolic compounds are shown in Fig. 6. HPTLC plates used for isolation of coumarin are shown in Fig. 7. HPTLC chromatogram (a) at $366 \mathrm{~nm}$ and (b) at $254 \mathrm{~nm}$.

HPTLC chromatogram for isolated phenolic compounds is shown in Fig. 8.

GC/MS chromatogram of the isolated coumarin

The mass peak of the compound was at $192 \mathrm{~m} / \mathrm{z}$.

GC/MS chromatogram of the isolated coumarin and its mass fragmentation are shown in Figs. 9 and 10, respectively. GC/MS chromatogram of isolated phenolic compound and its mass fragmentation are shown in Figs. 11 and 12, respectively.

\section{IR spectroscopy}

The IR spectral analysis of the isolated coumarin showed the peaks at $3333.10,2947.33,1697.41,1606.76,1508.38$, and $860.28 \mathrm{~cm}^{-1}$.

Table 1: Preliminary examination of the ethyl acetate fraction for phenols, flavonoids, and coumarin

\begin{tabular}{lllll}
\hline Part used & Fraction & Phenols & Coumarins & Flavonoids \\
\hline Leaves & $\begin{array}{l}\text { Ethyl } \\
\text { acetate }\end{array}$ & + & + & + \\
\hline
\end{tabular}

Table 2: Retention time in minutes of standard coumarins and phenolic acids

\begin{tabular}{ll}
\hline Standard material & Retention time \\
\hline Scopoletin & 7.2 \\
Gallic acid & 3.8 \\
\hline
\end{tabular}

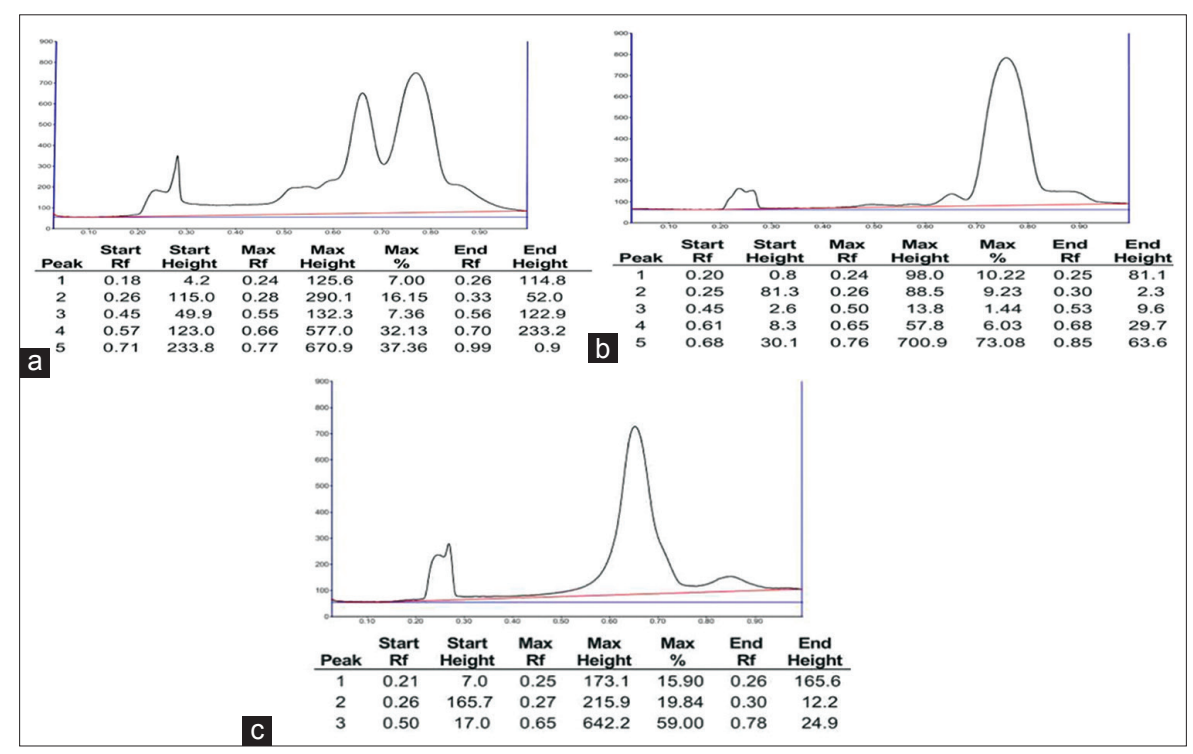

Fig. 4: (a) Track 1: High-performance thin-layer chromatography (HPTLC) of ethyl acetate fraction. (b) Track 2: HPTLC of standard scopoletin. (c) Track 2: HPTLC of standard gallic acid 

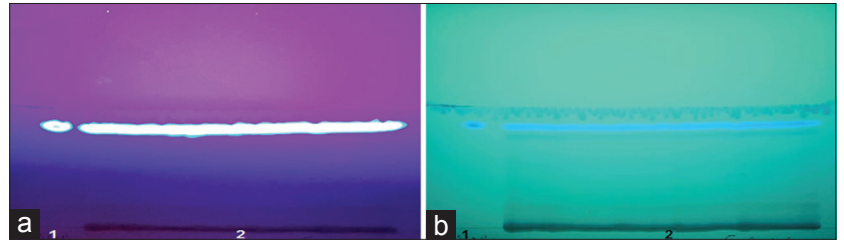

Fig. 5: Preparative thin-layer chromatography for standard scopoletin (1) and ethyl acetate fraction (2) and on silica gel $\mathbf{~ G F}_{25}$ detection by ultraviolet light (a) at $254 \mathrm{~nm}$ and (b) at $366 \mathrm{~nm}$

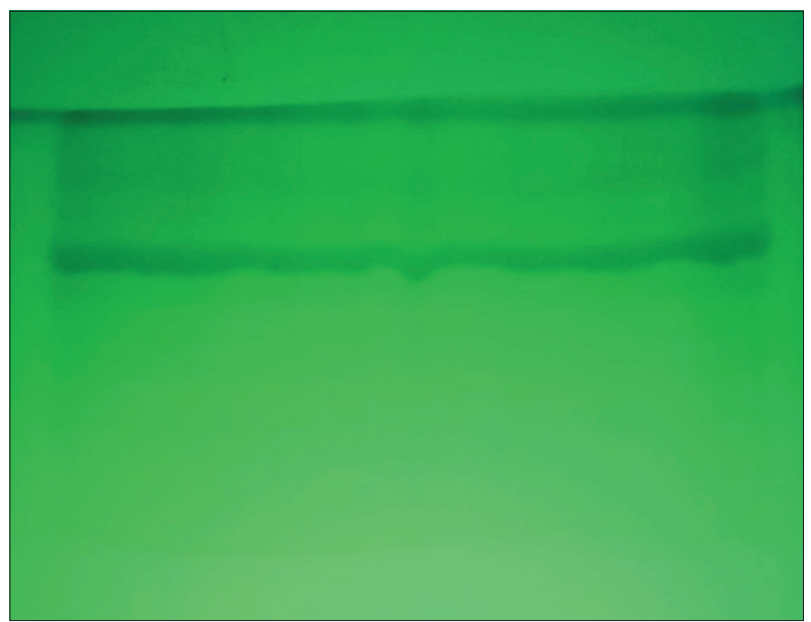

Fig. 6: Preparative thin-layer chromatography chromatogram of phenolic acid isolation

On the other hand, the IR spectral analysis of the isolated phenolic compound showed the peaks at 2900-3400, 3265.59, 3377.47, 1695.49, 1539.25, and 1612.54.

The IR spectra of the isolated coumarin and isolated phenol is shown in Figs. 13 and 14, respectively.

UV spectrum of the isolated coumarin and phenolic compound is shown in Figs. 15 and 16, respectively.

\section{DISCUSSION}

Natural products have always been a preferred choice of all as it plays a great role in discovering new medicines. During extraction, solvents diffuse into the solid plant material and solubilize compounds with similar polarity. Extraction and separation of chemical constituents of plants depend on selective solvents through standard procedure.

Coumarins are a class of natural compounds widely distributed in plants has an important role in the healthcare and various traditional medicine systems of the world.

Fractionation is the best method to separate each group of constituents alone when the plant contains several groups of constituents.

The preliminary phytochemical analysis confirmed the presence of coumarin, phenols, and flavonoids. Ethyl acetate extract of cold method, which was further subjected for isolation yielded faintyellow crystals. In the IR spectral analysis, the peak at 3333.10 $\mathrm{cm}^{-1}$, a broad band is most probably the result of $\mathrm{O}-\mathrm{H}$ stretching vibrations of phenol $\mathrm{OH}$ group. The peak at $2947.33 \mathrm{~cm}^{-1}$ showed $\mathrm{C}-\mathrm{H}$ stretching due to $-\mathrm{CH} 3$. The peak at $1697.41 \mathrm{~cm}^{-1}$ indicates the presence of $-\mathrm{C}=0$, carbonyl group. The peak at $1606.76 \mathrm{~cm}^{-1}$

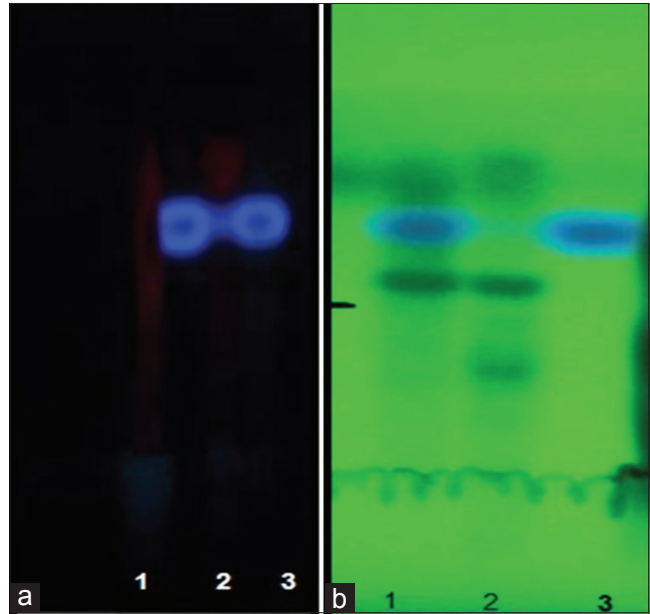

Fig. 7: High-performance thin-layer chromatography plates for 1-ethyl acetate fraction and 3-standard scopoletin, detection under ultraviolet light (a) at $366 \mathrm{~nm}$ and (b)at $254 \mathrm{~nm}$

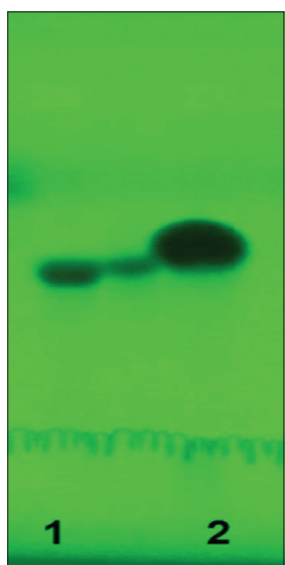

Fig. 8: High-performance thin-layer chromatography plates of analyzed fractions with reference standards, detection under ultraviolet light at $254 \mathrm{~nm}$ (1 - Ethyl acetate isolated fraction, 2 - Standard gallic acid)

showed the presence of $-\mathrm{CH}=\mathrm{CH}$ group. The peak at $1508.38 \mathrm{~cm}^{-1}$ indicates the presence of benzene ring. The peak at $860.28 \mathrm{~cm}^{-1}$ showed the presence of disubstitution of benzene ring of isolated compound. On the basis of mass spectrum, The molecular weight of isolated coumarins detected in the GC/MS at m/z 192. The UV florescence, HPLC, and HPTLC results are similar to that of standard scopoletin [41]. All the above results confirm that the isolated compound is scopoletin.

Scopoletin, which is a coumarin derivative, has been found in many plant species and has several antimicrobial activities as well as pharmacological effects. The compound is also one of the major constituents from the related species of Chenopodium. The present study also revealed the presence of scopoletin as one of the major constituents of the species $C$. murale.

The IR spectrum of the isolated phenolic compound revealed the presence of carboxylic group (2900-3400 $\mathrm{cm}^{-1}$ ), hydroxyl phenolic groups (3377.47 $\left.\mathrm{cm}^{-1}\right)$, carbonyl group (1695.49 $\mathrm{cm}^{-1}$ ), and an aromatic moiety $(1539.25,1612.54)$. On the basis of mass spectrum, The molecular weight of isolated phenolic acid detected in the GC/MS at $\mathrm{m} / \mathrm{z}$ 171. UV-visible spectrum of gallic acid in methanol is observed 


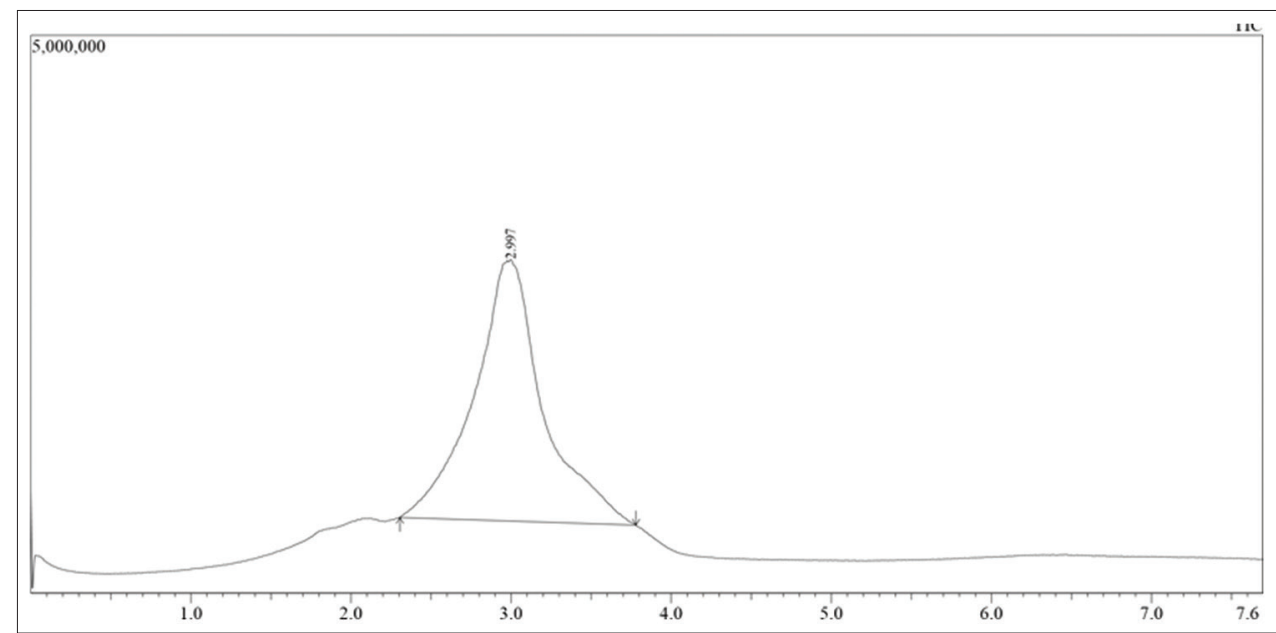

Fig. 9: Gas chromatography/mass spectrometry chromatogram of isolated coumarin

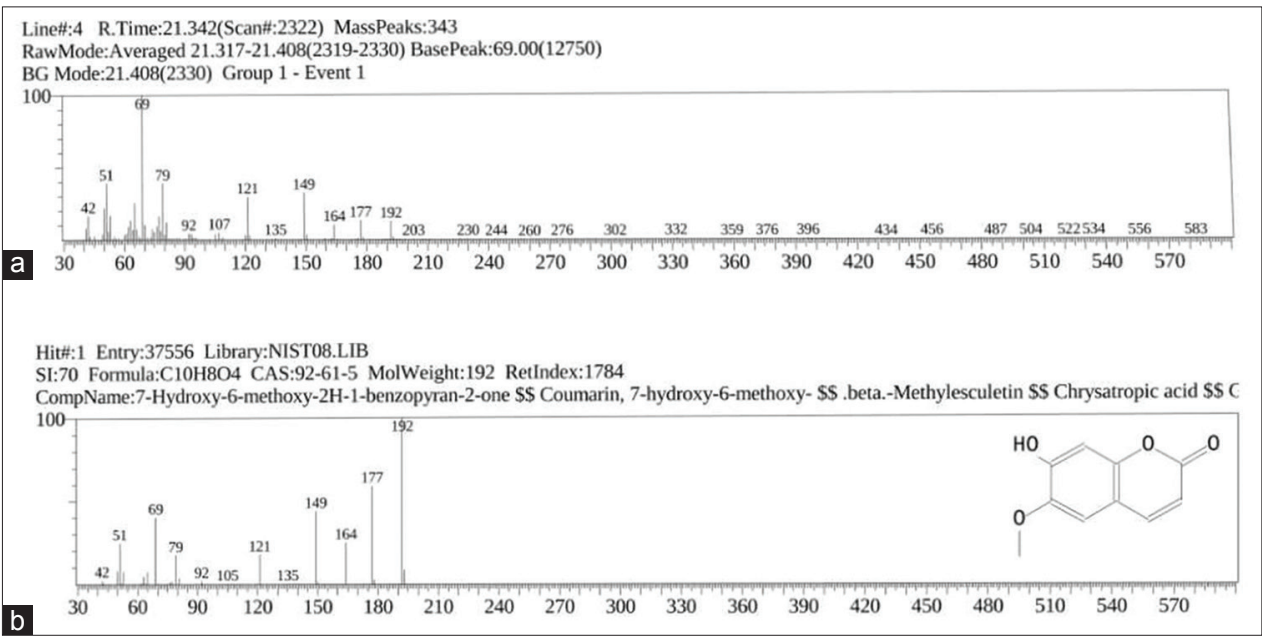

Fig. 10: Mass fragmentation spectra of (a) isolated coumarin and (b) standard scopoletin

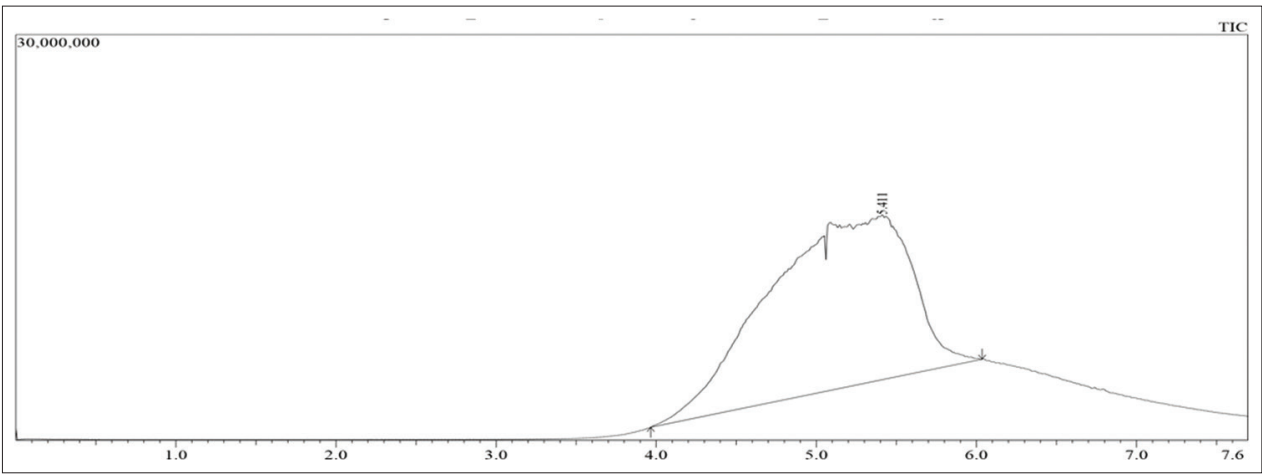

Fig. 11: Gas chromatography/mass spectrometry chromatogram of isolated phenolic acid

at $310 \mathrm{~nm}[42,43]$. The HPLC and HPTLC in addition to the above results coincide with that reported for gallic acid.

The importance of this study is that it is the first study which confirms the presence of scopoletin and gallic acid in the Iraqi species of $C$. murale.

Structure activity relationships of coumarin and 4-hydroxycoumarin do not possess anticoagulant activity. Link, who pioneered the isolation and characterization of bis' hydroxycoumarin (dicoumarol) from sweet clover, concluded that the minimal requirements for anticoagulant activity are 4-hydroxy group, a 3-substituent, and a bis molecule [44].

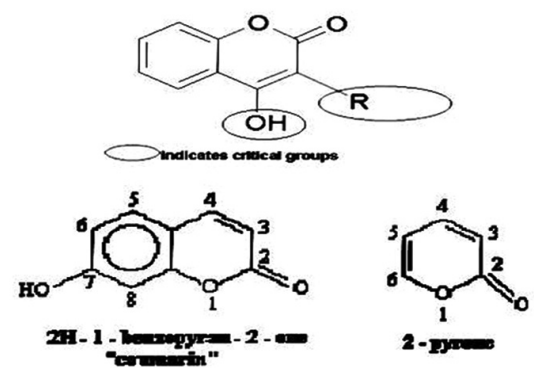




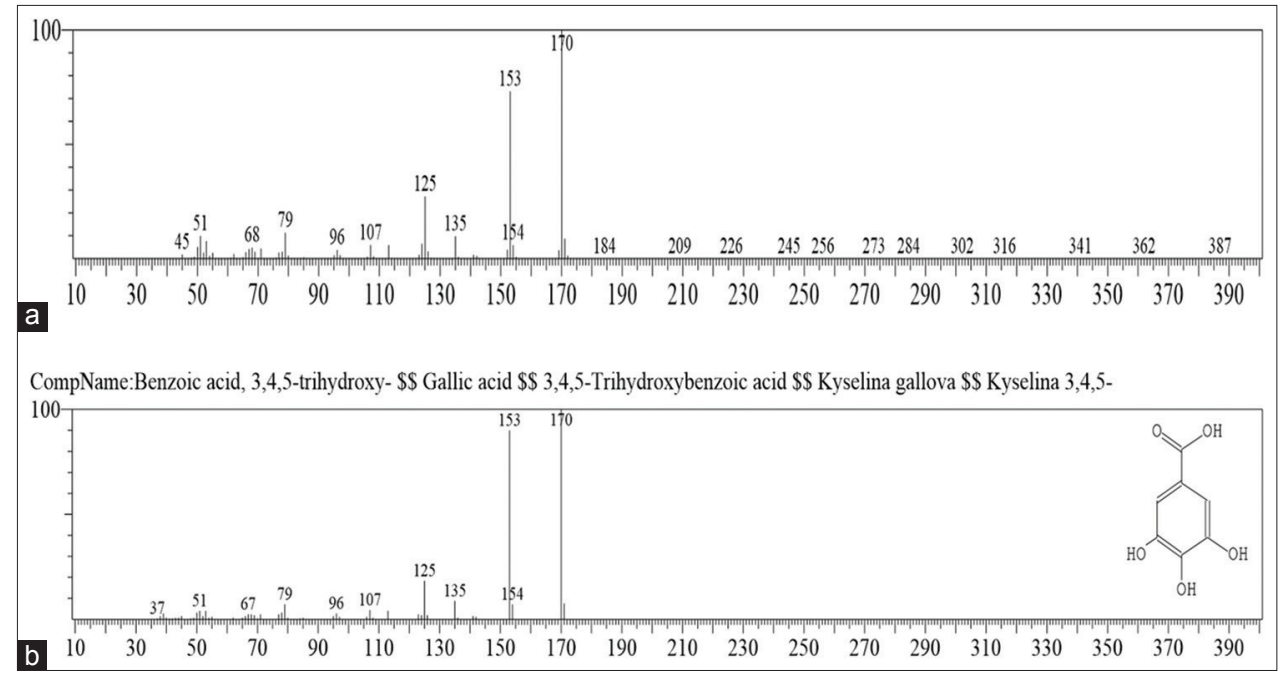

Fig. 12: Mass fragmentation spectra of (a) isolated phenolic compound and (b) standard gallic acid

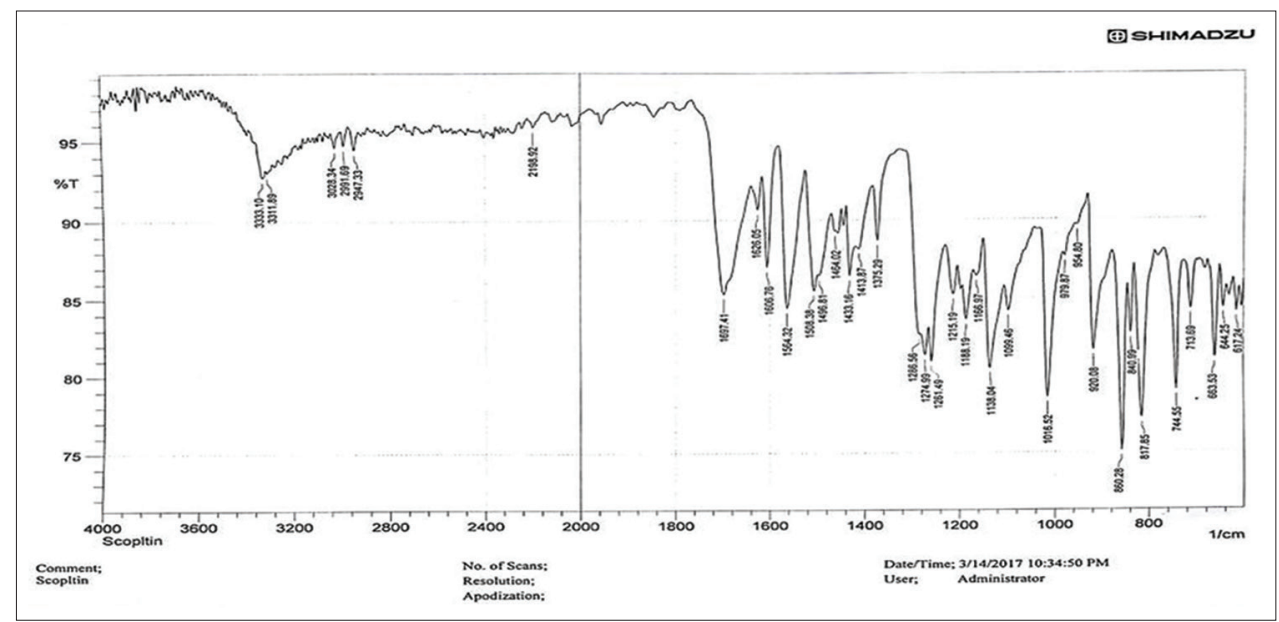

Fig. 13: Infrared spectrum of isolated coumarin

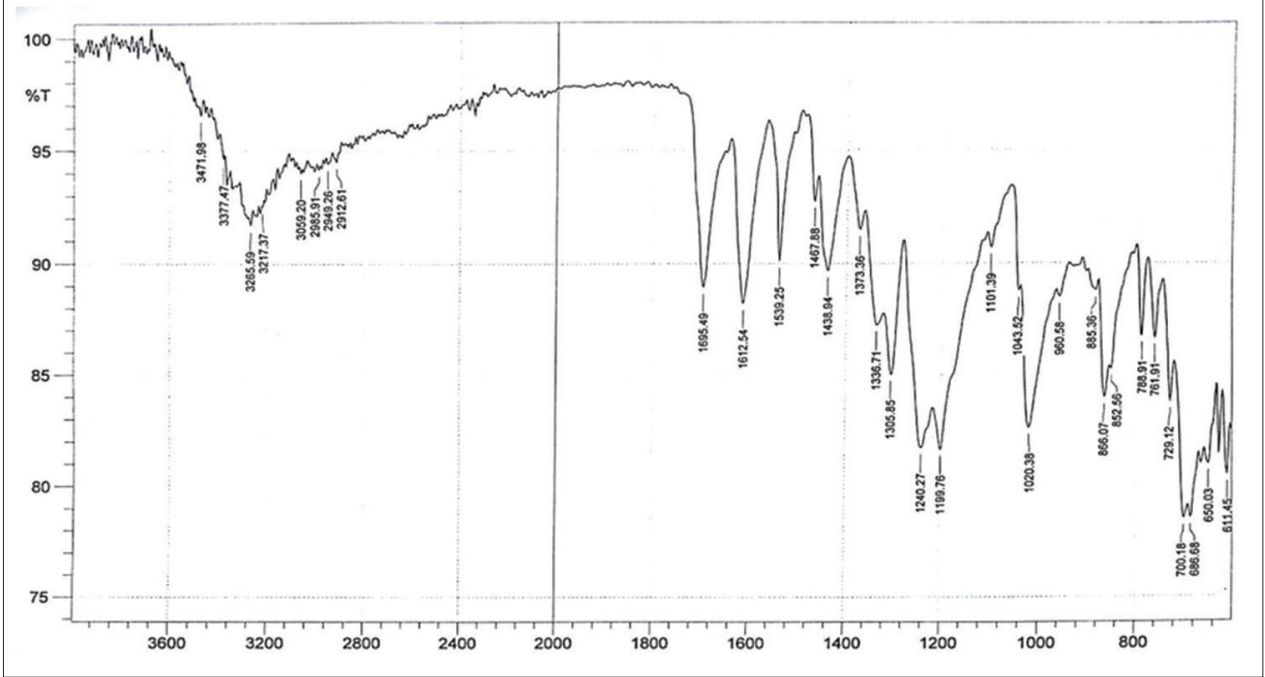

Fig. 14: Infrared spectrum of isolated phenolic compound 


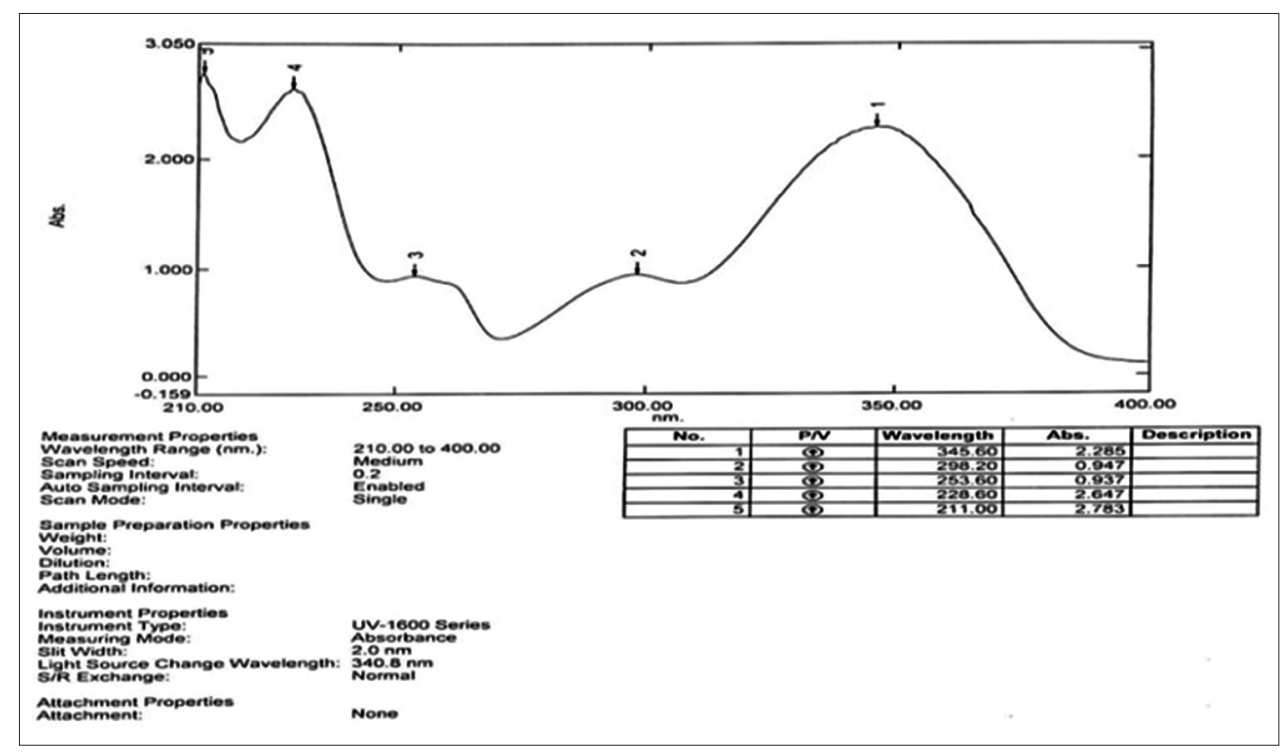

Fig. 15: Ultraviolet spectrum of isolated coumarin

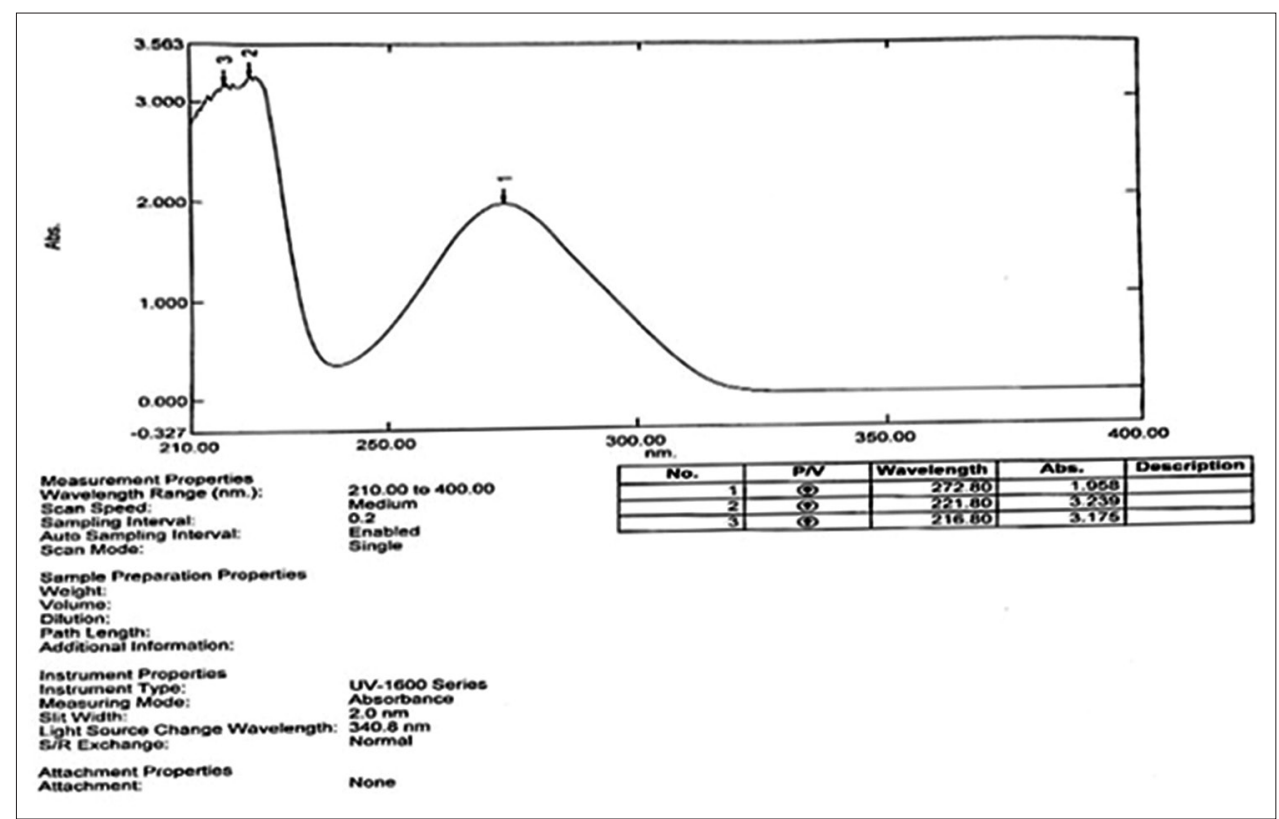

Fig. 16: Ultraviolet spectrum of isolated phenolic compound

The benzo-2-pyrone nucleus of the simple coumarins derives from the phenyl acrylic skeleton of cinnamic acids.

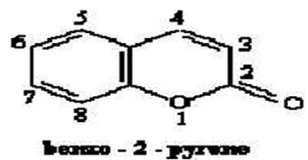

The coumarin structure is derived from cinnamic acid through orthohydroxylation, trans-cis isomerization of the side chain double bond and lactonization. The trans form is stable and could not cyclise, and therefore, there should be isomerization of some sort and the enzyme isomerase is implicated.

Scopoletin is the most widespread coumarins in nature. Thus, this biosynthesis pathway showed that all coumarins oxygenated at position 9 [45].

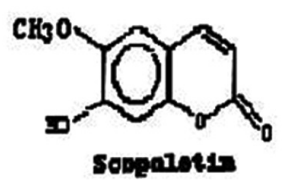

\section{CONCLUSION}

The results of the current study showed the presence of coumarin derivative, i.e., scopoletin and a phenolic acid which is gallic acid in the ethyl acetate fraction.

\section{ACKNOWLEDGMENT}

Financial support and deeply grateful to the College of Pharmacy, University of Baghdad, for giving us the opportunity and facilities to achieve this work. 


\section{REFERENCES}

1. Fuentes-Bazan S, Uotila P, Borsch T. A novel phylogeny-based generic classification for Chenopodium sensu lato, and a tribal rearrangement of Chenopodioideae (Chenopodiaceae). Willdenowia 2012;1(42):14.

2. Kütz. BSBI List 2007. Botanical Society of Britain and Ireland. The Original (xls) on 2015-01-25. [Last retrieved on 2014 Oct 17].

3. Chenopodiastrum murale. Germplasm Resources Information Network (GRIN). Agricultural Research Service (ARS), United States Department of Agriculture (USDA). [Last retrieved 2013 Jul 09].

4. Marie CN. Gardens of Hawaii. Honolulu, HI, USA: Bishop Museum Press; 1965. p. 331.

5. Boulos L. Medicinal Plants of North Africa. Algonac, MI: Reference Publications; 1983. p. 103.

6. Watt JM, Breyer-Brandwijk MG. The Medicinal and Poisonous Plants of Southern and Eastern Africa. $2^{\text {nd }}$ ed. London, UK: E and S Lining Stone Ltd.; 1962. p. 1457.

7. Vasishita PC. Taxonomy of Angiosperms. India: Ram Chand; 1989. p. 648.

8. Gohar AA, Maatooq GT, Niwa M. Two flavonoid glycosides from Chenopodium murale. Phytochemistry 2000;53(2):299-303.

9. Lozoya J, Lozoya M. Flora Medicinal de Mexico, Primera Part: Plantas in Digenas. Mexico: Instituto Mexicano del Seguro Social; 1982. p. 31.

10. Rustenbekova GB, Goryaev MI, Nizhinskaya GA. Flavonoids of Chenopodium botrys. Khim Prir Soedin Tashk 1994;3:406.

11. De Pascual TJ, Torres C, Gonzalez MS, Grande M, Bellido IS. Delta-5hydro-1-hydroxy carvomenthols from the essential oil of Chenopodium multifidum. Phytochemistry 1983;22:2749-52.

12. Bahrman N, Jay M, Gorenflot R. Contribution to the chemosystematic knowledge of some species of genus Chenopodium. Lett Bot 1985;2:107-13.

13. Ahmad AG, Maatooq GT, Niwa M. Two flavonoid glycosides from Chenopodium murale. Phytochemistry 2000;53:299-303.

14. El-Sayed NH, Awaad AS, Hifnawy MS, Mabry TJ. A flavonol triglycoside from Chenopodium murale. Phytochemistry 1999;51:591-3.

15. van Rompuy L, Zeevaart J. Are steroidal oestrogens natural plants constituents. Phytochemistry 1979;18:863-6.

16. Bathory M, Toth I, Szendrei K, Reisch J. Ecdysteroids in Spinacia oleraceae and Chenopodium bonus. Phytochemistry 1982;21:236-8.

17. Rizk AM. Constituents of plants growing in Qatar. Fitoterapia 1986;57:3-9

18. Rizk AM. The Photochemistry of Flora of Qatar. London: King Print of Richmond; 1986. p. 30-2.

19. Aritomi M, Kawasaki T. Photochemistry. In: Boulos L, editor. Medicinal Plants of North Africa. Vol. 23. Algonac, MI: Reference Publications Inc.; 1984. p. 2043.

20. Zhao Y, Liu F, Lou HX. Studies on the chemical constituents of Solanum nigrum. Zhong Yao Cai 2010;33(4):555-6.

21. Ouzir M, El-Bairi K, Amzazi S. Toxicological properties of fenugreek (Trigonella foenum graecum). Food Chem Toxicol Int J Publ Br Ind Biol Res Assoc 2016;96:145-54.

22. Ma J, Jones SH, Hecht SM. A coumarin from Mallotus resinosus that mediates DNA cleavage. J Nat Prod 2004;67(9):1614-6.

23. Corbett JT. The scopoletin assay for hydrogen peroxide. A review and a better method. J Biochem Biophys Methods 1989;18(4):297-307.

24. Shaw CY, Chen CH, Hsu CC, Chen CC, Tsai YC. Antioxidant properties of scopoletin isolated from Sinomonium acutum. Phytother Res 2003;17(7):823-5.

25. Ojewole JA, Adesina SK. Mechanism of the hypotensive effect of scopoletin isolated from the fruit of Tetrapleura tetraptera. Planta Med 1983;49(1):46-50

26. Capra JC, Cunha MP, Machado DG, Zomkowski AD, Mendes BG,
Santos AR, et al. Antidepressant-like effect of scopoletin, a coumarin isolated from Polygala sabulosa (Polygalaceae) in mice: Evidence for the involvement of monoaminergic systems. Eur J Pharmacol 2010;7:232-8

27. Carpinella MC, Ferrayoli CG, Palacios SM. Antifungal synergistic effect of scopoletin, a hydroxycoumarin isolated from Melia azedarach L. Fruits. J Agric Food Chem 2005;8:2922-7.

28. Cheng AS, Cheng YH, Chang TL. Scopoletin attenuates allergy by inhibiting Th2 cytokines production in EL-4 T cells. Food Funct 2012;3(8):886-90

29. Pan R, Dai Y, Gao X, Xia Y. Inhibition of vascular endothelial growth factor-induced angiogenesis by scopoletin through interrupting the auto phosphorylation of VEGF receptor 2 and its downstream signaling pathways. Vasc Pharmacol 2011;54:18-28.

30. Tanaka Y, Data ES, Hirose S, Taniguchi T, Uritani I. Biochemical changes in secondary metabolites in wounded and deteriorated cassava roots. Agric Biol Chem 1983;47:603-700.

31. Uritani I. Biochemistry on postharvest metabolism and eterioration of some tropical tuberous crops. Bot Bull Acad Sin 1999;40:177-83.

32. Buschmann H, Rodriguez MX, Thome J, Beeching J. Accumulation of hydroxycoumarins during post-harvest deterioration of tuberous roots of cassava (Manihot esculenta Crantz). Ann Bot 2000;86:1153-60.

33. Giesemann A, Biehl B, Lieberei R. Identification of scopoletin as a phytoalexin of the rubber tree Hevea brasiliensis. J Phytopathol 2008;117:373-6.

34. Liu XL, Zhang L, Fu XL, Chen K, Qian BC. Effect of scopoletin on PC3 cell proliferation and apoptosis. Acta Pharmacol Sin 2001;22(10):929-33.

35. Manuele MG, Ferraro G, Barreiro Arcos ML, López P, Cremaschi G, Anesini C. Comparative immunomodulatory effect of scopoletin on tumoral and normal lymphocytes. Life Sci 2006;79(21):2043-8.

36. Panda S, Kar A. Evaluation of the ant thyroid, ant oxidative and ant hyperglycemic activity of scopoletin from Aegle marmelos leaves in hyperthyroid rats. Phytother Res 2006;20(12):1103-5.

37. Obasi SC, Njoku OU, Obidoa O. Effects of single oral doses of scopoletin and aflatoxin B1 on the clotting time, serum cholesterol and phospholipid levels of chicks. Indian J Physiol Pharmacol 1994;38(2):89-94

38. Wirasutisna KR, Prabowo WC, Insanu M. Isolation and characterization of 3-acetyl aleuritolic acid and scopoletin from stem bark of Aleurites moluccana (L.) Willd. Int J Pharm Pharm Sci 2013;5(7):851-3.

39. Sampath M. Isolation and identification of gallic acid from Polyalthia longifolia (Sonn.) Thawaites. Int J Pharm Bio Sci 2013;4(2):966-72.

40. Kumari S. Evaluation of phytochemical analysis and antioxidant and antifungal activity of Pithecellobium dulce leaves' extract. Asian J Pharm Pharm Sci 2017;1(10):370-5.

41. Bhatt MK, Dholwani KK, Saluja A. Isolation and structure elucidation of scopoletin from Ipomoea reniformis (Convolvulaceae). J Appl Pharm Sci 2011;1(5):138-44.

42. Abri A, Maleki M. Isolation and identification of gallic acid from the Elaeagnus angustifolia leaves and determination of total phenolic, flavonoids contents and investigation of antioxidant activity. Iran Chem Commun 2016;41:46-154

43. Chanwitheesuk A, Teerawutgulrag A, Kilburn JD, Nuansri R. Antimicrobial Gallic acid from Caesalpinia mimosoides Lamk. Food Chem 2005;100(3):1044-8

44. Chen H, Walsh CT. Synthesis of novel N-substituted-2-oxo$2 \mathrm{H}$ - 1-coumarin-3-carboxamide and evaluated for selective anti helicobacter pylori activity and cytotoxicity. Chem Biol 2001;8:288-301.

45. Jain PK, Himanshu J. Coumarin: Chemical and pharmacological profile. J Appl Pharm Sci 2012;2(6):236-40. 